\title{
Ambulatory anesthesia and postoperative nausea and vomiting: predicting the probability
}

This article was published in the following Dove Press journal:

Ambulatory Anesthesia

29 August 2016

Number of times this article has been viewed

\author{
Aoife T Hegarty' \\ Muiris A Buckley' \\ Conan L McCaul'-3 \\ ' Department of Anaesthesia, \\ The Rotunda Hospital, ${ }^{2}$ Mater \\ Misericordiae University Hospital, \\ ${ }^{3}$ School of Medicine and Medical \\ Science, University College Dublin, \\ Dublin, Ireland
}

Correspondence: Conan L McCaul Department of Anaesthesia, The Rotunda Hospital, Parnell Square, Dublin I, Ireland Tel +353 I8I7 I794

Email cmccaul@rotunda.ie

\begin{abstract}
Nausea and vomiting are distinctly unpleasant symptoms that may occur after surgery and anesthesia, and high priority is given to their prevention by patients. Research in this area is plentiful and has focused on event prediction and pharmacological prophylaxis but despite this, postoperative nausea and vomiting (PONV) typically occurs in $20 \%-30 \%$ of patients in contemporary practice. Prediction of postoperative and postdischarge nausea and vomiting is particularly important in the ambulatory surgical population as these symptoms may occur following discharge from hospital and continue for up to one week when access to antiemetic therapies is limited. Many of the existing predictive scoring systems are based on data from inpatient populations and limited to the first 24 hours after surgery. Scoring systems based on data from ambulatory surgical populations to predict PONV are only moderately good. The best-performing systems in ambulatory patients are those of Sinclair and Sarin with an area under the receiver operating characteristic curve of 0.78 and 0.74 , respectively, but are limited by the short duration of follow-up and a greater emphasis on nausea than vomiting. Given that the ability to predict both PONV and postdischarge nausea and vomiting is clearly limited, emphasis has been placed on prophylactic strategies that incorporate antiemetic medication, intravenous hydration, and nonnarcotic analgesia. PONV has been reduced to $<10 \%$ in institutions using multimodal approaches. Scoring systems may facilitate "risk tailoring" in which patient risk profile is used as a stratification method for pharmacointervention.
\end{abstract}

Keywords: postoperative nausea and vomiting, prediction, antiemetics, anesthesia

\section{Introduction}

Nausea and vomiting are distinctly unpleasant sensations that may occur after surgery and anesthesia. Prevention and treatment of these symptoms are of particular importance in ambulatory anesthesia. Although rarely the cause of major morbidity, they occur relatively frequently and may result in prolonged recovery room or hospital stays or unanticipated admission, adding cost and inconvenience to a patient's experience. ${ }^{1,2}$ Patients who become nauseated or vomit stay on average an extra 20-25 minutes in the postanesthetic care unit (PACU). ${ }^{3}$ In the ambulatory population, nausea and vomiting may occur or recur following discharge when patients have limited access to effective treatment. For patients, prevention of postoperative nausea and vomiting (PONV) ranks as high as pain control as a health care priority after surgery. Prevention of PONV is one of the extensively studied areas in perioperative medicine, and numerous interventions, pharmacological and nonpharmacological, are proven by double-blind placebo-controlled randomized trials to reduce but unfortunately not eliminate the 
incidence of these symptoms. Established clinical practice encourages clinicians to identify patients at risk of PONV and use a multimodal approach to prevent its occurrence. This review focuses on current approaches to risk prediction and reduction. Prediction of risk is important as not all patients will experience PONV even if not given antiemetic prophylaxis, and therefore, it is of clinical importance to identify patients who might benefit from interventions. In this way, patients who are not at risk of PONV would not receive medications that they have little likelihood of benefitting from, and they would also avoid the risk of possible side effects. The ability to accurately predict PONV coupled with an effective prophylactic or treatment strategy would result in avoidance of symptoms, faster recovery, and increased patient satisfaction, limit the occurrence of side effects, and improve resource utilization.

\section{Postdischarge nausea and vomiting}

Postdischarge nausea and vomiting (PDNV) is experienced by $35 \%-49 \%$ of patients and may continue for up to one week. ${ }^{46}$ Pain may be an additional risk factor for late PDNV. ${ }^{5}$ PDNV is particularly concerning, as patients may have limited access to effective therapies, and untreated symptoms have a significant impact on quality of life, functional status, and satisfaction. ${ }^{5}$ The ability to accurately predict PDNV would be arguably more valuable than PONV as it would allow clinicians to provide easier access to interventions, eg, longer-acting agents and oral or transdermal preparations. In a multicenter study of 2,170 adults undergoing ambulatory anesthesia, Apfel identified a number of risk factors for PDNV, such as female sex, age $<50$ years, a history of nausea or vomiting, and opioid administration or nausea in the postanesthesia care unit. Depending on the number of risk factors, the patient's risk for PDNV was predicted as $7 \%, 20 \%, 28 \%, 53 \%, 60 \%$, and $89 \%$, broadly in keeping with PONV prediction (Figure 1). ${ }^{6}$ The area under the receiver operating characteristic curve (AUC ROC) was 0.72 .

\section{Economics of PONV}

The ability to accurately predict the risk of PONV would also have economic advantage by reducing the PACU stay and the amount of medication used unnecessarily. ${ }^{7}$ Kumar et $\mathrm{al}^{3}$ recently estimated the cost of PONV prophylaxis at STG $£ 70$ per case in a UK practice. The cost of the more commonly administered antiemetic agents has decreased substantially in recent years, and acquisition costs have become less of an issue. ${ }^{8,9}$ Parra-Sanchez et $\mathrm{al}^{4}$ in the United States calculated

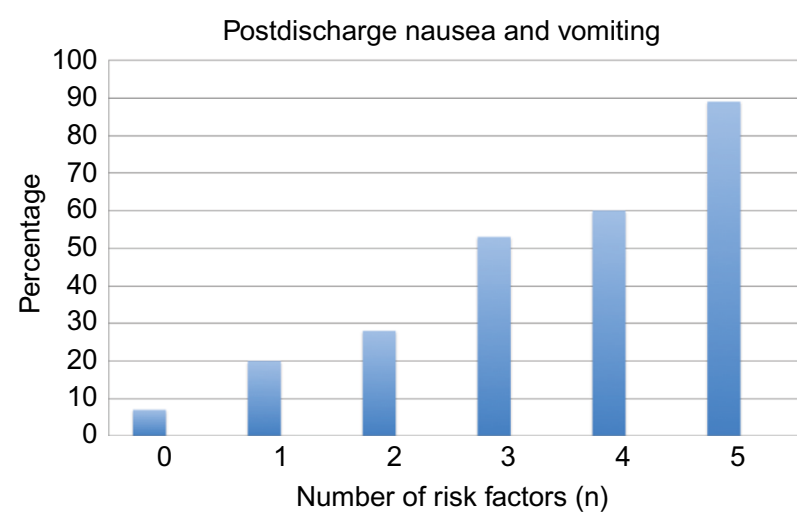

Figure I Projected incidence of postdischarge nausea and vomiting using the Apfel score.

Notes: The factors considered are female sex, age $<50$ years, nausea in the postanesthetic care unit, prior history of PONV, and postoperative opioid administration.

Abbreviation: PONV, postoperative nausea and vomiting.

that PONV added an incremental cost of $\$ 75$ per patient, which given an institutional incidence of PONV of $37 \%$ projects to $\$ 2,775$ per hundred patients. Habib et a ${ }^{10}$ also estimated that the occurrence of nausea and vomiting added USD 85 and 138, respectively, mainly through increased time in PACU and associated nursing costs.

\section{Pathophysiology of PONV}

The physiology of PONV is complex and not fully understood. The centers for coordinating vomiting are located throughout the pons and medulla. The chemoreceptor trigger zone (CTZ) and the nucleus tractus solitarius (NTS) receive input, which can contribute to nausea and vomiting (Figure 2). The CTZ then projects to the NTS, which triggers vomiting by stimulating multiple other nuclei (rostral nucleus, nucleus ambiguous, ventral respiratory group, and the dorsal motor nucleus of the vagus). The CTZ receives input from vagal afferents in the gastrointestinal tract. As it is located in the area postrema of the fourth ventricle outside the blood-brain barrier, it can also be stimulated by emetogenic drugs, toxins, and metabolites in the blood and cerebrospinal fluid. The NTS receives input from vagal afferents and from the vestibular and limbic apparatus; therefore, it is sensitive to motion sickness. It also appears to receive input directly from the cerebral cortex in anxiety-induced nausea. There are multiple neurotransmitter pathways involved in transmitting these signals: $5 \mathrm{HT}_{3}$ is the principal neurotransmitter for vagal afferents to the CTZ, dopamine- 2 transmits from the CTZ to the NTS, and the vestibular apparatus uses histamine- 1 and acetylcholine as its neurotransmitters. PONV can be triggered by various stimuli acting on different neurotransmitter 


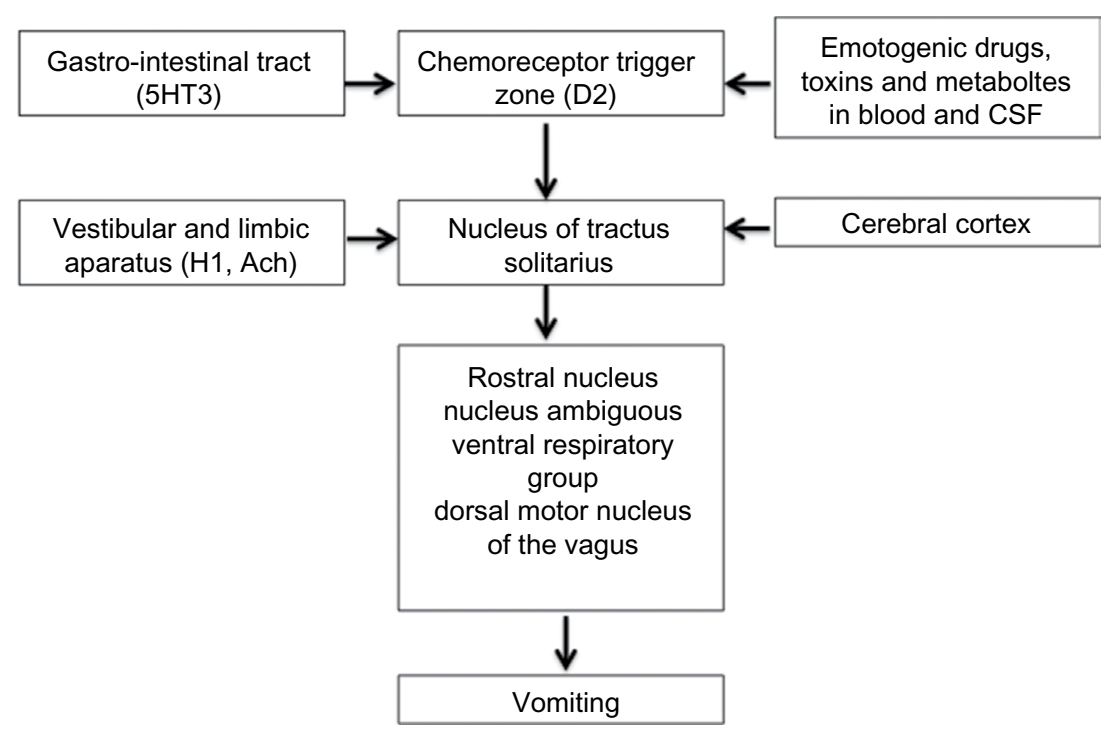

Figure 2 Pathophysiology of nausea and vomiting after anesthesia and surgery.

pathways, including anxiety, pain, drugs, and motion. There are several different classes of antiemetic medications available targeting these different pathways (vide infra).

\section{Antiemetics: risks and benefits}

A large number of drugs have been shown in well-designed trials to prophylactically reduce PONV with numbers needed to treat ranging from 2 to $9 .{ }^{11-17}$ It is estimated that even the most effective agents reduce the symptoms in only $25 \%-30 \%$ of those who receive them. Since a patient is likely to experience simultaneous activation of multiple emetogenic pathways, the use of drugs that act on different pathways is logical. Used in combination, antiemetic agents from different classes have greater efficacy than used alone. ${ }^{18}$ Although in theory, the use of multiple drugs at lower individual doses is more effective than single therapy, evidence for antagonism between some antiemetic agents is evolving. ${ }^{19}$

Available antiemetic agents include $5 \mathrm{HT}_{3}$ receptor antagonists, corticosteroids, neurokinin-1 receptor antagonists, butyrophenones, antihistamines, anticholinergics, benzodiazepines, alpha- 2 agonists, and phenothiazines. More recently, investigated interventions include gabapentin and mirtazapine that act at $5 \mathrm{HT}_{3}$ and histamine receptors. ${ }^{20}$ Other drugs can influence PONV through omission or substitution, eg, opioids, volatile anesthetic agents, nitrous oxide, and reversal agents. Given the range of options and dose variations, it is perhaps unsurprising that no optimal combination of agents has been determined. In a Cochrane review of 737 studies involving 103,237 patients, Carlisle and Stevenson ${ }^{21}$ studied eight proven antiemetics and estimated that in a population experiencing a $30 \%$ incidence of PONV, administration of a proven antiemetic would benefit only $10 \%$. The remainder would not benefit but would be exposed to side effects. A study aiming to investigate all possible combinations of single fixed doses of eight drugs would require 256 groups. Overall, side effects are usually mild and are estimated to be experienced by $4 \%$ of those who receive them. ${ }^{21}$ The side effects of the drug classes are as follows: $5 \mathrm{HT}_{3}$ receptor antagonists: headache, elevated liver enzymes, constipation, and QTc prolongation in higher doses; ${ }^{22}$ corticosteroids: hyperglycemia, shortened duration of rocuronium-induced neuromuscular blockade, perineal pruritus, and bradycardia, ${ }^{23-26}$ the incidence of postoperative wound infections does not appear to increase following the use of dexamethasone; ${ }^{27} \mathrm{NK}-1$ receptor antagonists: dizziness, headaches, and constipation, ${ }^{28,29}$ butyrophenones: sedation, hypotension, and extrapyramidal symptoms, ${ }^{22}$ pathological QTc prolongation does not occur with doses used for PONV prophylaxis; ${ }^{30}$ antihistamines: sedation, dry mouth, and constipation, ${ }^{29,31}$ anticholinergic agents: dry mouth, drowsiness, and visual disturbances, ${ }^{32}$ benzodiazepines: sedation; ${ }^{33}$ alpha-2 agonists: hypotension and sedation; phenothiazines: sedation; ${ }^{34}$ gabapentin: somnolence and dizziness $;{ }^{35}$ PC6 acupoint stimulation: skin irritation, blistering, redness, and pain. ${ }^{36}$

\section{Risk factor prediction}

Internationally agreed consensus guidelines advocate that a clinician assesses each individual patient's risk of PONV using a validated risk score based on independent predictors. ${ }^{9}$ The characteristics of a useful risk score are clinical credibility, accuracy, generalizability, and clinical effectiveness. ${ }^{39}$ The ability of different scoring systems to predict PONV can be compared using the AUC ROC..$^{38} \mathrm{~A}$ perfect predictive system 
Table I Risk factors used to predict development of PONV

\begin{tabular}{|c|c|c|c|c|c|c|c|c|c|}
\hline Authors & Sex & $\begin{array}{l}\text { Smoking } \\
\text { status }\end{array}$ & $\begin{array}{l}\text { History of } \\
\text { PONV }\end{array}$ & Opioids & $\begin{array}{l}\text { Duration of } \\
\text { surgery }\end{array}$ & $\begin{array}{l}\text { Motion } \\
\text { sickness }\end{array}$ & $\begin{array}{l}\text { Type of } \\
\text { surgery }\end{array}$ & Age & $\begin{array}{l}\text { Type of } \\
\text { anesthesia }\end{array}$ \\
\hline Apfel et $\mathrm{al}^{44}$ & + & + & + & + & - & + & - & - & - \\
\hline Koivuranta et $\mathrm{al}^{42}$ & + & + & + & - & - & + & - & - & - \\
\hline Palazzo and Evans ${ }^{4 !}$ & + & - & + & + & - & + & - & - & - \\
\hline Sinclair et $\mathrm{al}^{45}$ & + & + & + & - & + & - & + & + & + \\
\hline Sarin et $\mathrm{al}^{48}$ & + & - & + & + & + & + & + & + & + \\
\hline Junger et $\mathrm{al}^{46}$ & + & + & - & + & + & - & - & - & + \\
\hline
\end{tabular}

Abbreviation: PONV, postoperative nausea and vomiting.

would have a score of 1.0 and a system no better than chance a score of 0.5 . Currently used predictive scores identify risk factors in specific surgical populations using logistic regression techniques. These comprise patient, surgical, and anesthesiarelated factors (Table 1). A recent meta-analysis of 95,154 patients analyzed symptom occurrence after anesthesia and confirmed the following risk factors: sex (female $>$ male), previous history of PONV, motion sickness, nonsmoking status, postoperative opioid administration, type of anesthesia (general $>$ regional, volatile $>$ total intravenous anesthesia, and nitrous oxide use), younger age, and greater duration of anesthesia. ${ }^{39}$ Lower incidences of PONV are seen in patients who had peripheral, and to a lesser extent, central neuraxial blockade. ${ }^{40,41}$ The choice of airway device (supraglottic airway vs endotracheal tube) has not been shown to be clinically relevant. ${ }^{42}$ Interestingly, intraoperative use of Bispectral Index (BIS) monitoring has recently been shown to be associated with a lower incidence of severe PONV than non-BIS monitored patients, a finding ascribed to lower total dose of maintenance anesthetic agents. ${ }^{43}$ Surgical site has not been consistently shown to influence risk of PONV.

In the original studies of PONV risk, different importance (mathematical weighting) was assigned to each factor. Palazzo and Evans ${ }^{44}$ studied patients undergoing minor orthopedic surgery and identified female sex, opioids, and previous history of nausea as independent risk factors. These were incorporated into a complex equation that generated a probability of symptom occurrence during the time window studied in the original data set, eg, 0-24 hours postoperatively. ${ }^{44,45}$ Such equations are sufficiently unwieldy to be impractical for bedside use and have been simplified for clinical utility. ${ }^{46}$ Simplified scores such as those of Apfel and Koivuranta have been shown to be as accurate as their more complex original equations (Figure 3). In the Apfel score, the factors considered are female sex, nonsmoking status, prior history of PONV or motion sickness, and, finally, likelihood of postoperative opioid administration. Patients with no risk factors will have $\sim 10 \%$ incidence of PONV. Patients with 1, 2, 3, and 4 factors will have approximate incidences of $20 \%, 40 \%, 60 \%$, and $80 \%$,
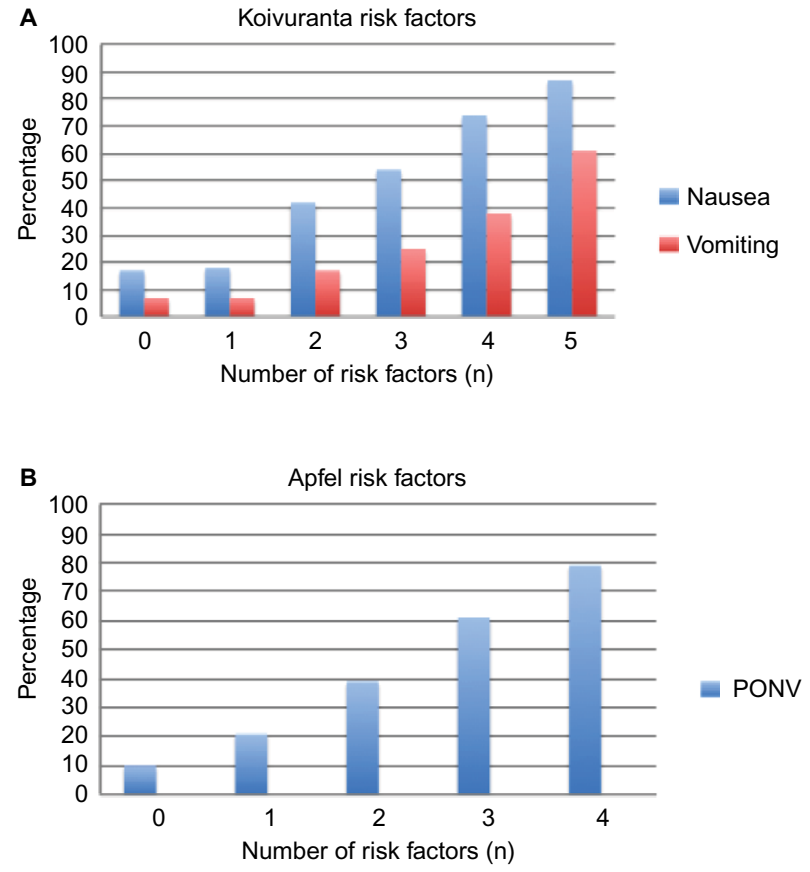

Figure 3 Koivuranta and Apfel Scores

Notes: (A) Projected incidence of PONV using the Koivuranta score. The factors considered are female sex, nonsmoking status, prior history of PONV, postoperative opioid administration, and duration of surgery $>60$ minutes. (B) Projected incidence of PONV using the Apfel score. The factors considered are: female sex, nonsmoking status, prior history of PONV or motion sickness, and postoperative opioid administration.

Abbreviation: PONV, postoperative nausea and vomiting.

respectively (Figure 3A) ${ }^{47}$ Koivuranta's system that was also simplified uses duration of surgery ( $>60$ minutes) in addition to the aforementioned Apfel factors (Figure $3 \mathrm{~A}$ and B). ${ }^{45}$ Overlap between these systems is not surprising as they were based in part on the same data set. In Koivuranta's system, the presence of $0,1,2,3,4$, and 5 factors resulted in a predicted incidence of nausea of $17 \%, 18 \%, 42 \%, 54 \%, 74 \%$, and $87 \%$, respectively. Sinclair et a ${ }^{48}$ additionally determined that surgery type (plastic and orthopedic in particular), general anesthesia, and younger age increased the risk of PONV. Using an anesthesia information management system, Junger et $\mathrm{l}^{49}$ created an algorithm to predict PONV in PACU using female sex, smoking status, age, duration of surgery, intraoperative use of opioids, use of $\mathrm{N}_{2} \mathrm{O}$, and intravenous anesthesia with propofol. 
Table 2 AUC ROC for emetic symptoms

\begin{tabular}{|c|c|c|c|c|}
\hline \multirow[t]{2}{*}{ Authors } & \multirow{2}{*}{$\begin{array}{l}\text { Duration of } \\
\text { follow-up } \\
\text { (hours) }\end{array}$} & \multirow{2}{*}{$\begin{array}{l}\text { Patient } \\
\text { population }\end{array}$} & \multicolumn{2}{|c|}{ AUC ROC } \\
\hline & & & PONV & Vomiting \\
\hline Apfel et al ${ }^{44}$ & $0-24$ & Inpatient & 0.7 & 0.73 \\
\hline Koivuranta et $\mathrm{al}^{42}$ & $0-24$ & Inpatient & 0.71 & 0.73 \\
\hline Palazzo and Evans ${ }^{4 !}$ & $0-24$ & Inpatient & 0.68 & 0.66 \\
\hline Sinclair et $\mathrm{al}^{45}$ & $0-24$ & Ambulatory & 0.78 & - \\
\hline Sarin et $\mathrm{al}^{48}$ & Unspecified & Ambulatory & 0.74 & - \\
\hline Junger et $\mathrm{al}^{46}$ & Unspecified* & Mixed & 0.76 & - \\
\hline Peng et $\mathrm{al}^{49}$ & $0-24$ & Inpatient & 0.82 & - \\
\hline
\end{tabular}

Note: *Data were collected during PACU stay, the '-' indicates no data.

Abbreviations: AUC ROC, area under the receiver operating characteristic curve; $\mathrm{PACU}$, postanesthetic care unit; PONV, postoperative nausea and vomiting.

The AUC ROC for the most widely used scoring systems is broadly similar with a range of $0.68-0.78$ (Table 2) ${ }^{44-50}$ Prediction based on surgical site alone is particularly poor with an AUC ROC of $0.53 .{ }^{51}$ None has exceeded 0.8 even using highly sophisticated methodology and thus cannot be considered any better than moderately good. Advanced computer technology based on local data sets in the form of an artificial neural network has been shown to be somewhat superior to any of the aforementioned eponymous scoring systems but still falls well short of perfection and remains in the range of "moderately good". 52,53

\section{Using scoring systems}

A practical issue encountered by clinicians using current risk scores is that certain risks cannot be evaluated when assessing risk factors. Although certain risk factors are binary, eg, male versus female, others are not. A patient who has never had an anesthetic before clearly does not have a history of PONV but may well be in a high-risk group. Alternatively, a patient who had a previous anesthetic but did not have PONV may not have experienced symptoms because they received antiemetics. Patients may also confuse delayed opioid-induced nausea with PONV. Additionally, neither the likelihood of postoperative opioid administration nor the duration of surgery can be known with absolute certainty. It is also unclear whether infrequent smokers should be categorized identical to heavy smokers. Similar issues relate to quantification of motion sickness. Thus, arguably, in a proportion of patients, many elements of a scoring system cannot be used with confidence.

\section{Ability of risk factors scoring systems to predict PONV in different populations}

A general principle of effective scoring systems is that they also predict events in different patient populations than those used to develop the original model. ${ }^{37}$ Toner et $\mathrm{al}^{54}$ found Palazzo's model to correctly predict the proportion of patients with PONV but only predicted $71 \%$ correctly for an individual patient. The score worked best for patients at highest risk. Thomas et $\mathrm{al}^{55}$ compared four predictive scoring systems in a gynecological surgery population, all of whom received prophylactic antiemetics. Wide variations in prediction were evident. At the Academic Medical Centre of the University of Amsterdam, the Netherlands, van den Bosch et $\mathrm{al}^{56}$ found that the Apfel score predicted very few patients with PONV in those with few risk factors and overestimated PONV in those with multiple risk factors. Engel et $\mathrm{al}^{57}$ compared four scoring systems in a population with a low incidence of PONV and found that the AUC ROC of the Koivuranta model (0.62) and that of the Apfel model (0.63) were poorer than those achieved by the authors. The Sinclair (0.7) and Junger models (0.7) performed somewhat better. ${ }^{57}$ The applicability of scoring systems across ethnic groups is the subject of ongoing research. Rodseth et al, ${ }^{58}$ in a multiethnic South African population, found that the incidence of PONV varied between ethnic groups and was lowest in black South Africans. Adult risk scores have not been found to reliably predict risk in pediatric populations. ${ }^{59}$ Factors predicting PONV in pediatrics include age ( $>3$ years), duration of surgery ( $>30$ minutes), strabismus surgery, and a family history of PONV. ${ }^{59}$ Predictive systems based on "traditional" volatile anesthesia have been found to overestimate risk in xenon-based anesthesia. ${ }^{60}$

\section{Incidence of PONV in contemporary practice}

The average PONV rate in contemporary practice is thought to be $\sim 20 \%-30 \% .{ }^{61}$ Examination of control groups in recent randomized controlled trials representing "usual care" in academic institutions shows even higher incidences. In a recent study of 1,483 patients, the incidence of PONV in the patient group who were subject to risk assessment and therapeutic recommendation was $42 \%$. The "care as usual" group had an overall incidence of PONV of $50 \%$. This ranged from $23 \%$ to $82 \%$ depending on risk profile. ${ }^{62} \mathrm{~A}$ prior study from the same investigators yielded a $42 \%$ incidence of PONV in the "care as usual" group. ${ }^{63}$ Ziemann-Gimmel et a ${ }^{64}$ recently reported an incidence of $37.3 \%$ of PONV in bariatric patients who had volatile-based general anesthesia all of whom who received triple prophylaxis. White et al ${ }^{65}$ reported a $45 \%$ requirement for rescue antiemetics in patients who had a minimum of two Apfel risk factors.

In the ENIGMA (Evaluation of Nitrous Oxide in the Gas Mixture for Anaesthesia) trial, which was primarily intended 
to investigate the effect of nitrous oxide administration on mortality, antiemetic administration was left to the discretion of the attending anesthetists. Severe PONV occurred in $16.6 \%$ of patients and was associated with female sex (odds ratio [OR] 2.06), age $<55$ years (OR 1.38), abdominal surgery (OR 1.74), $\mathrm{N}_{2} \mathrm{O}$ administration (OR 2.5), duration of surgery $>3.5$ hours (OR 1.23-1.53), and the absence of BIS monitoring (OR 0.66). ${ }^{43}$ In Spanish and Portuguese University Teaching Hospitals, the reported incidence of PONV was identical at 34\%. ${ }^{66,67}$

\section{Reducing baseline risk - importance of nonpharmacological interventions - hydration and acustimulation Hydration}

A number of well-conducted studies have investigated the effect of intravenous fluids in PONV. ${ }^{68}$ McCaul et al ${ }^{69}$ failed to find any benefit of balanced crystalloid in quantities targeted to replace fasting volume-deficit patients undergoing gynecological laparoscopy. In a similar patient population, larger quantities of fluid $(30 \mathrm{~mL} / \mathrm{kg})$ did, however, reduce PONV substantially. ${ }^{70}$ Pulmonary function was not adversely affected at these volumes, but it should be recognized that the patients in these studies did not have cardiorespiratory disease, and equivalent volumes of fluid may not be appropriate to all patient populations and surgeries. ${ }^{71}$ Intravenous fluid administration has also been shown to reduce pain after laparoscopic surgery. ${ }^{71,72}$ The results of the studies investigating colloids are conflicting. ${ }^{73}$ Preoperative oral carbohydrate drinks taken 2 hours preoperatively have been shown to reduce $\mathrm{PONV}^{74}$

\section{Acustimulation}

A recent Cochrane review assessed the literature regarding stimulation of the wrist acupuncture point PC6 for preventing PONV and found the technique to be noninferior to pharmacological antiemetics. ${ }^{36}$

\section{Implementation gaps}

There is ample evidence that antiemetic prophylaxis is underutilized by providers..$^{29,75}$ In Scotland, Brampton et $\mathrm{al}^{76}$ reported only a $67 \%$ adherence to local PONV guidelines and a 58\% incidence of PONV. In the US, 61\% and 52\% compliances were reported for prophylaxis and rescue medication, respectively, in accordance with the American Society of Anesthesiologists and American Society of Peri-Anesthesia Nurses clinical practice guidelines. ${ }^{65}$ In that study, conducted in an academic teaching center, $8 \%$ of patients did not receive any prophylactic antiemetic agents despite each having a high-risk profile. Compliance with institutional protocols is improved somewhat by educational strategies and decision prompting. ${ }^{77,78}$ Kappen et $\mathrm{al}^{79}$ recently reported their investigation into the failure of risk-prompting strategy for PONV to influence patient outcome. The reluctance of the clinicians to change practice was based in part on risk management, ie, the lack of risk-benefit consideration for drugs. Additional factors were the low priority given to PONV as an important health care outcome and the reliance on intuition to make decisions regarding prophylaxis. ${ }^{79}$

\section{Variations in clinical practice}

Leading experts argue for more liberal use of multimodal pharmacoprophylaxis irrespective of risk profile on the basis of proven efficacy and the modest cost and relatively benign side effect profile of antiemetics. ${ }^{61}$ This included triple antiemetic prophylaxis, total intravenous anesthesia, intravenous hydration, nonsteroidal anti-inflammatory agents, and the avoidance of muscle relaxation. ${ }^{80}$ Eberhart et $\mathrm{al}^{81}$ achieved similarly low incidence of PONV (7\%) using a multimodal approach that included prophylactic antiemetics. An alternative approach is "risk tailoring", in which patient risk profile is used as a stratification method for pharmacointervention. ${ }^{82}$ Using this approach, Pierre et al ${ }^{82}$ reported a $15.5 \%$ incidence of PONV using multidrug prophylaxis in the highest risk group and $14.3 \%$ in the lowest risk group, achieved without antiemetic prophylaxis. The third approach is to treat symptoms of patient as they arise. ${ }^{83}$ The obvious drawback of this approach is the knowledge that PONV will occur commonly and might require an anesthetist to regularly leave the operating room to administer medication. The symptoms of PONV are not reliably detected in busy PACUs and might go untreated and worsen subsequently in ward areas where administration of intravenous agents is more difficult. ${ }^{84}$

\section{Future directions}

Given that PONV is influenced by local practice, it is intuitive that local data sets would be usefully incorporated into predictive models to generate site-relevant predictive scores. Such an approach has been generated by Junger et al, ${ }^{49}$ who used routinely collected information from an anesthesia information management system at Justus Liebig University Giessen. Based on the analysis of 15 anesthesia-related, ten patientrelated, and four postoperative factors, the computerized system automatically calculated PONV risk. In this way, risk factor prediction can be incorporated into decision-making aids, such as computer pop-up windows. This has been shown 
to substantially increase the use of antiemetics administered as prophylaxis. ${ }^{77}$ Smartphone-based applications may have similar utility in the future.

Pharmacogenomics has future implications for PONV prevention and treatment. Attempts to identify genetic loci that contribute to PONV are ongoing. ${ }^{85}$ Investigations have shown that homozygous patients with the A118 variant of OPRM1 are at higher risk of $P O N V .{ }^{85}$ Rueffert et $\mathrm{l}^{86}$ investigated variants of the serotonin receptor subunits A and B for genetic variants in 95 patients who had suffered from PONV and found patterns that were associated with an increased risk of postoperative vomiting. In a study of $5 \mathrm{HT}_{3}$ antagonists in chemotherapyinduced nausea, slow metabolizers of CYP2D6 substrates had high tropisetron levels, and ultrarapid metabolizers had higher frequency of vomiting than all the other patients. ${ }^{87}$

\section{Summary}

PONV remains a common clinical problem despite the availability of predictive scoring systems and efficacious interventions. The ability of scoring systems to predict the incidence of PONV in untreated patients is relatively consistent. The thresholds at which clinicians should initiate prophylactic medication regimens are less clear. This may explain in part why antiemetic prophylaxis based on risk stratification has been shown to reduce but not eliminate the incidence of PONV. ${ }^{82,88,89}$ Clinicians should bear in mind that even if a perfect predictive system for PONV or PDNV were developed, these symptoms will persist until the perfect antiemetic strategy is established.

\section{Disclosure}

The authors report no conflicts of interest in this work.

\section{References}

1. Carroll NV, Miederhoff P, Cox FM, Hirsch JD. Postoperative nausea and vomiting after discharge from outpatient surgery centers. Anesth Analg. 1995;80(5):903-909.

2. Mattila K, Toivonen J, Janhunen L, Rosenberg PH, Hynynen M. Postdischarge symptoms after ambulatory surgery: first-week incidence, intensity, and risk factors. Anesth Analg. 2005;101(6):1643-1650.

3. Kumar A, Ong T, MacLeod G, Brampton W. Prophylaxis of postoperative nausea and vomiting: an audit of current practice and cost. Anaesthesia. 2007;62(3):311-312.

4. Parra-Sanchez I, Abdallah R, You J, et al. A time-motion economic analysis of postoperative nausea and vomiting in ambulatory surgery. Can J Anaesth. 2012;59(4):366-375.

5. Odom-Forren J, Jalota L, Moser DK, et al. Incidence and predictors of postdischarge nausea and vomiting in a 7-day population. J Clin Anesth. 2013;25(7):551-559.

6. Apfel CC, Philip BK, Cakmakkaya OS, et al. Who is at risk for postdischarge nausea and vomiting after ambulatory surgery? Anesthesiology. 2012;117(3):475-486.

7. Carroll NV, Miederhoff PA, Cox FM, Hirsch JD. Costs incurred by outpatient surgical centers in managing postoperative nausea and vomiting. J Clin Anesth. 1994;6(5):364-369.
8. Bartlett R, Hartle AJ. Routine use of dexamethasone for postoperative nausea and vomiting: the case against. Anaesthesia. 2013;68(9):892-896.

9. Gan TJ, Diemunsch P, Habib AS, et al; Society for Ambulatory Anesthesia. Consensus guidelines for the management of postoperative nausea and vomiting. Anesth Analg. 2014;118(1):85-113.

10. Habib AS, Chen YT, Taguchi A, Hu XH, Gan TJ. Postoperative nausea and vomiting following inpatient surgeries in a teaching hospital: a retrospective database analysis. Curr Med Res Opin. 2006;22(6):1093-1099.

11. De Oliveira GS Jr, Castro-Alves LJ, Chang R, Yaghmour E, McCarthy RJ. Systemic metoclopramide to prevent postoperative nausea and vomiting: a meta-analysis without Fujii's studies. Br JAnaesth. 2012;109(5):688-697.

12. De Oliveira GS Jr, Castro-Alves LJ, Ahmad S, Kendall MC, McCarthy RJ. Dexamethasone to prevent postoperative nausea and vomiting: an updated meta-analysis of randomized controlled trials. Anesth Analg. 2013;116(1):58-74.

13. Singh PM, Borle A, Rewari V, et al. Aprepitant for postoperative nausea and vomiting: a systematic review and meta-analysis. Postgrad Med J. 2016;92(1084):87-98.

14. Liang X, Zhou M, Feng JJ, et al. Efficacy of dexmedetomidine on postoperative nausea and vomiting: a meta-analysis of randomized controlled trials. Int J Clin Exp Med. 2015;8(8):12113-12134.

15. Grant MC, Kim J, Page AJ, Hobson D, Wick E, Wu CL. The effect of intravenous midazolam on postoperative nausea and vomiting: a metaanalysis. Anesth Analg. 2016;122(3):656-663.

16. Tricco AC, Soobiah C, Blondal E, et al. Comparative efficacy of serotonin (5-HT3) receptor antagonists in patients undergoing surgery: a systematic review and network meta-analysis. BMC Med. 2015; 13:136.

17. Loewen PS, Marra CA, Zed PJ. 5-HT3 receptor antagonists vs traditional agents for the prophylaxis of postoperative nausea and vomiting. Can J Anaesth. 2000;47(10):1008-1018.

18. Apfel CC, Korttila K, Abdalla M, et al. IMPACT Investigators. A factorial trial of six interventions for the prevention of postoperative nausea and vomiting. N Engl J Med. 2004;350(24):2441-2451.

19. Carlisle JB. A meta-analysis of prevention of postoperative nausea and vomiting: randomised controlled trials by Fujii et al. compared with other authors. Anaesthesia. 2012;67(10):1076-1090.

20. Chang FL, Ho ST, Sheen MJ. Efficacy of mirtazapine in preventing intrathecal morphine-induced nausea and vomiting after orthopaedic surgery. Anaesthesia. 2010;65(12):1206-1211.

21. Carlisle JB, Stevenson CA. Drugs for preventing postoperative nausea and vomiting. Cochrane Database Syst Rev. 2006;(3):CD004125.

22. Charbit B, Albaladejo P, Funck-Brentano C, Legrand M, Samain E, Marty J. Prolongation of QTc interval after postoperative nausea and vomiting treatment by droperidol or ondansetron. Anesthesiology. 2005;102(6):1094-1100.

23. Henzi I, Walder B, Tramèr MR. Dexamethasone for the prevention of postoperative nausea and vomiting: a quantitative systematic review. Anesth Analg. 2000;90(1):186-194.

24. Waldron NH, Jones CA, Gan TJ, Allen TK, Habib AS. Impact of perioperative dexamethasone on postoperative analgesia and sideeffects: systematic review and meta-analysis. Br J Anaesth. 2013; 110(2):191-200.

25. Soltész S, Fraisl P, Noé KG, Hinkelbein J, Mellinghoff H, Mencke T. Dexamethasone decreases the duration of rocuronium-induced neuromuscular block: a randomised controlled study. Eur J Anaesthesiol. 2014;31(8):417-422.

26. Neff SP, Stapelberg F, Warmington A. Excruciating perineal pain after intravenous dexamethasone. Anaesth Intensive Care. 2002;30(3):370-371.

27. Assante J, Collins S, Hewer I. Infection associated with single-dose dexamethasone for prevention of postoperative nausea and vomiting: a literature review. AANA J. 2015;83(4):281-288.

28. Diemunsch P, Joshi GP, Brichant JF. Neurokinin-1 receptor antagonists in the prevention of postoperative nausea and vomiting. Br J Anaesth. 2009;103(1):7-13.

29. Kranke P, Eberhart LH. Possibilities and limitations in the pharmacological management of postoperative nausea and vomiting. Eur J Anaesthesiol. 2011;28(11):758-765. 
30. Sneyd JR. Droperidol: past, present and future. Anaesthesia. 2009;64(11): 1161-1164.

31. Kranke P, Morin AM, Roewer N, Eberhart LH. Dimenhydrinate for prophylaxis of postoperative nausea and vomiting: a meta-analysis of randomized controlled trials. Acta Anaesthesiol Scand. 2002;46(3): $238-244$.

32. Apfel CC, Zhang K, George E, et al. Transdermal scopolamine for the prevention of postoperative nausea and vomiting: a systematic review and meta-analysis. Clin Ther. 2010;32(12):1987-2002.

33. Ahn EJ, Kang H, Choi GJ, Baek CW, Jung YH, Woo YC. The effectiveness of midazolam for preventing postoperative nausea and vomiting: a systematic review and meta-analysis. Anesth Analg. 2016;122(3): 664-676.

34. Schnabel A, Eberhart LH, Muellenbach R, Morin AM, Roewer N, Kranke P. Efficacy of perphenazine to prevent postoperative nausea and vomiting: a quantitative systematic review. Eur J Anaesthesiol. 2010;27(12):1044-1051.

35. Achuthan S, Singh I, Varthya SB, Srinivasan A, Chakrabarti A, Hota D. Gabapentin prophylaxis for postoperative nausea and vomiting in abdominal surgeries: a quantitative analysis of evidence from randomized controlled clinical trials. Br J Anaesth. 2015;114(4):588-597.

36. Lee A, Chan SK, Fan LT. Stimulation of the wrist acupuncture point PC6 for preventing postoperative nausea and vomiting. Cochrane Database Syst Rev. 2015;11:CD003281.

37. Altman DG, Vergouwe Y, Royston P, Moons KG. Prognosis and prognostic research: validating a prognostic model. BMJ. 2009;338:b605.

38. Hanley JA, McNeil BJ. The meaning and use of the area under a receiver operating characteristic (ROC) curve. Radiology. 1982;143(1):29-36.

39. Apfel CC, Heidrich FM, Jukar-Rao S, et al. Evidence-based analysis of risk factors for postoperative nausea and vomiting. Br JAnaesth. 2012;109(5): 742-753.

40. Liu SS, Strodtbeck WM, Richman JM, Wu CL. A comparison of regional versus general anesthesia for ambulatory anesthesia: a metaanalysis of randomized controlled trials. Anesth Analg. 2005;101(6): 1634-1642.

41. Borgeat A, Ekatodramis G, Schenker CA. Postoperative nausea and vomiting in regional anesthesia: a review. Anesthesiology. 2003;98(2):530-547.

42. Porhomayon J, Farid SD, El-Solh AA, Adlparvar G, Nader ND. The impact of endotracheal tube vs. laryngeal mask airway on the incidence of postoperative nausea and vomiting: a systemic review and metaanalysis. Middle East J Anaesthesiol. 2015;23(1):9-16.

43. Leslie K, Myles PS, Chan MT, et al; ENIGMA Trial Group. Risk factors for severe postoperative nausea and vomiting in a randomized trial of nitrous oxide-based vs nitrous oxide-free anaesthesia. Br J Anaesth. 2008;101(4):498-505.

44. Palazzo M, Evans R. Logistic regression analysis of fixed patient factors for postoperative sickness: a model for risk assessment. Br J Anaesth. 1993;70(2):135-140.

45. Koivuranta M, Läärä E, Snåre L, Alahuhta S. A survey of postoperative nausea and vomiting. Anaesthesia. 1997;52(5):443-449.

46. Apfel CC, Kranke P, Eberhart LH, Roos A, Roewer N. Comparison of predictive models for postoperative nausea and vomiting. Br J Anaesth. 2002;88(2):234-240.

47. Apfel CC, Läärä E, Koivuranta M, Greim CA, Roewer N. A simplified risk score for predicting postoperative nausea and vomiting: conclusions from cross-validations between two centers. Anesthesiology. 1999;91(3):693-700.

48. Sinclair DR, Chung F, Mezei G. Can postoperative nausea and vomiting be predicted? Anesthesiology. 1999;91(1):109-118.

49. Junger A, Hartmann B, Benson M, et al. The use of an anesthesia information management system for prediction of antiemetic rescue treatment at the postanesthesia care unit. Anesth Analg. 2001;92(5): 1203-1209.

50. Sarin P, Urman RD, Ohno-Machado L. An improved model for predicting postoperative nausea and vomiting in ambulatory surgery patients using physician-modifiable risk factors. $\mathrm{J} \mathrm{Am} \mathrm{Med} \mathrm{Inform} \mathrm{Assoc.}$ 2012;19(6):995-1002.
51. Apfel CC, Kranke P, Eberhart LH. Comparison of surgical site and patient's history with a simplified risk score for the prediction of postoperative nausea and vomiting. Anaesthesia. 2004;59(11): 1078-1082.

52. Peng SY, Wu KC, Wang JJ, Chuang JH, Peng SK, Lai YH. Predicting postoperative nausea and vomiting with the application of an artificial neural network. Br J Anaesth. 2007;98(1):60-65.

53. Traeger M, Eberhart A, Geldner G, et al. [Prediction of postoperative nausea and vomiting using an artificial neural network]. Anaesthesist. 2003;52(12):1132-1138.

54. Toner CC, Broomhead CJ, Littlejohn IH, et al. Prediction of postoperative nausea and vomiting using a logistic regression model. BrJAnaesth. 1996;76(3):347-351.

55. Thomas R, Jones NA, Strike P. The value of risks scores for predicting postoperative nausea and vomiting when used to compare patient group in a randomised controlled trial. Anaesthesia. 2002;57(11): $1119-1128$.

56. van den Bosch JE, Kalkman CJ, Vergouwe Y, et al. Assessing the applicability of scoring systems for predicting postoperative nausea and vomiting. Anaesthesia. 2005;60(4):323-331.

57. Engel JM, Junger A, Hartmann B, et al. Performance and customization of 4 prognostic models for postoperative onset of nausea and vomiting in ear, nose, and throat surgery. J Clin Anesth. 2006;18(4):256-263.

58. Rodseth RN, Gopalan PD, Cassimjee HM, Goga S. Reduced incidence of postoperative nausea and vomiting in black South Africans and its utility for a modified risk scoring system. Anesth Analg. 2010;110(6):1591-1594.

59. Eberhart LH, Morin AM, Guber D, et al. Applicability of risk scores for postoperative nausea and vomiting in adults to paediatric patients. Br J Anaesth. 2004;93(3):386-392.

60. Schaefer MS, Apfel CC, Sachs HJ, et al. Predictors for postoperative nausea and vomiting after xenon-based anaesthesia. Br JAnaesth. 2015;115(1): 61-67.

61. Kranke P. General multimodal or scheduled risk-adopted postoperative nausea and vomiting prevention: just splitting hairs? $\mathrm{Br} J$ Anaesth. 2015;114(2):190-193.

62. Kappen TH, Vergouwe Y, van Wolfswinkel L, Kalkman CJ, Moons KG, van Klei WA. Impact of adding therapeutic recommendations to risk assessments from a prediction model for postoperative nausea and vomiting. Br J Anaesth. 2015;114(2):252-260.

63. Kappen TH, Moons KG, van Wolfswinkel L, Kalkman CJ, Vergouwe Y, van Klei WA. Impact of risk assessments on prophylactic antiemetic prescription and the incidence of postoperative nausea and vomiting: a cluster-randomized trial. Anesthesiology. 2014;120(2):343-354.

64. Ziemann-Gimmel P, Goldfarb AA, Koppman J, Marema RT. Opioidfree total intravenous anaesthesia reduces postoperative nausea and vomiting in bariatric surgery beyond triple prophylaxis. Br J Anaesth. 2014;112(5):906-911.

65. White PF, O'Hara JF, Roberson CR, Wender RH, Candiotti KA; POSTOP Study Group. The impact of current antiemetic practices on patient outcomes: a prospective study on high-risk patients. Anesth Analg. 2008;107(2):452-458.

66. Moreno C, Veiga D, Pereira H, Martinho C, Abelha F. Postoperative nausea and vomiting: incidence, characteristics and risk factors - a prospective cohort study. Rev Esp Anestesiol Reanim. 2013;60(5):249-256.

67. Dalila V, Pereira H, Moreno C, Martinho C, Santos C, Abelha FJ. Postoperative nausea and vomiting: validation of the Portuguese version of the postoperative nausea and vomiting intensity score. Braz $J$ Anesthesiol. 2013;63(4):340-346.

68. Apfel CC, Meyer A, Orhan-Sungur M, Jalota L, Whelan RP, JukarRao S. Supplemental intravenous crystalloids for the prevention of postoperative nausea and vomiting: quantitative review. $\mathrm{Br} J$ Anaesth. 2012;108(6):893-902.

69. McCaul C, Moran C, O'Cronin D, et al. Intravenous fluid loading with or without supplementary dextrose does not prevent nausea, vomiting and pain after laparoscopy. Can J Anaesth. 2003;50(5):440-444. 
70. Magner JJ, McCaul C, Carton E, Gardiner J, Buggy D. Effect of intraoperative intravenous crystalloid infusion on postoperative nausea and vomiting after gynaecological laparoscopy: comparison of 30 and 10 $\mathrm{ml} \mathrm{kg(-1).} \mathrm{Br} \mathrm{J} \mathrm{Anaesth.} \mathrm{2004;93(3):381-385.}$

71. Straub BD, Aslani A, Enohumah K, et al. Evaluation of the effect of intra-operative intravenous fluid on post-operative pain and pulmonary function: a randomized trial comparing 10 and $30 \mathrm{ml} \mathrm{kg(-1)} \mathrm{of} \mathrm{crystal-}$ loid. Ir J Med Sci. 2014;183(4):549-556.

72. Maharaj CH, Kallam SR, MalikA, Hassett P, Grady D, Laffey JG. Preoperative intravenous fluid therapy decreases postoperative nausea and pain in high risk patients. Anesth Analg. 2005;100(3):675-682. table of contents.

73. Hayes I, Rathore R, Enohumah K, Mocanu E, Kumar D, McCaul C. The effect of crystalloid versus medium molecular weight colloid solution on post-operative nausea and vomiting after ambulatory gynecological surgery - a prospective randomized trial. BMC Anesthesiol. 2012;12:15.

74. Hausel J, Nygren J, Thorell A, Lagerkranser M, Ljungqvist O. Randomized clinical trial of the effects of oral preoperative carbohydrates on postoperative nausea and vomiting after laparoscopic cholecystectomy. Br J Surg. 2005;92(4):415-421.

75. Franck M, Radtke FM, Baumeyer A, Kranke P, Wernecke KD, Spies CD [Adherence to treatment guidelines for postoperative nausea and vomiting. How well does knowledge transfer result in improved clinical care?]. Anaesthesist. 2010;59(6):524-528. German.

76. Brampton W, Dryburgh IR, Wynn-Hebden A, Kumar A. Simplified measures of postoperative nausea and vomiting do not transfer to other populations. Br J Anaesth. 2013;111(4):677-678.

77. Kooij FO, Klok T, Hollmann MW, Kal JE. Decision support increases guideline adherence for prescribing postoperative nausea and vomiting prophylaxis. Anesth Analg. 2008;106(3):893-898

78. Sigaut S, Merckx P, Peuch C, Necib S, Pingeon F, Mantz J. Does an educational strategy based on systematic preoperative assessment of simplified Apfel's score decrease postoperative nausea and vomiting? Ann Fr Anesth Reanim. 2010;29(11):765-769.

79. Kappen TH, van Loon K, Kappen MA, et al. Barriers and facilitators perceived by physicians when using prediction models in practice. J Clin Epidemiol. 2016;70:136-145.
80. Scuderi PE, James RL, Harris L, Mims GR 3rd. Multimodal antiemetic management prevents early postoperative vomiting after outpatient laparoscopy. Anesth Analg. 2000;91(6):1408-1414.

81. Eberhart LH, Mauch M, Morin AM, Wulf H, Geldner G. Impact of a multimodal anti-emetic prophylaxis on patient satisfaction in highrisk patients for postoperative nausea and vomiting. Anaesthesia. 2002;57(10):1022-1027.

82. Pierre S, Corno G, Benais H, Apfel CC. A risk score-dependent antiemetic approach effectively reduces postoperative nausea and vomiting - a continuous quality improvement initiative. Can J Anaesth. 2004;51(4): $320-325$.

83. Scuderi PE, James RL, Harris L, Mims GR 3rd. Antiemetic prophylaxis does not improve outcomes after outpatient surgery when compared to symptomatic treatment. Anesthesiology. 1999;90(2):360-371.

84. Franck M, Radtke FM, Apfel CC, et al. Documentation of post-operative nausea and vomiting in routine clinical practice. JInt Med Res. 2010;38(3): 1034-1041.

85. Janicki PK, Vealey R, Liu J, Escajeda J, Postula M, Welker K. Genomewide association study using pooled DNA to identify candidate markers mediating susceptibility to postoperative nausea and vomiting. Anesthesiology. 2011;115(1):54-64.

86. Rueffert H, Thieme V, Wallenborn J, et al. Do variations in the 5-HT3A and 5-HT3B serotonin receptor genes (HTR3A and HTR3B) influence the occurrence of postoperative vomiting? Anesth Analg. 2009;109(5): 1442-1447.

87. Kaiser R, Sezer O, Papies A, et al. Patient-tailored antiemetic treatment with 5-hydroxytryptamine type 3 receptor antagonists according to cytochrome P-450 2D6 genotypes. J Clin Oncol. 2002;20(12): 2805-2811.

88. Biedler A, Wermelt J, Kunitz O, et al. A risk adapted approach reduces the overall institutional incidence of postoperative nausea and vomiting. Can J Anaesth. 2004;51(1):13-19.

89. Kranke P, Eberhart LH, Gan TJ, Roewer N, Tramer MR. Algorithms for the prevention of postoperative nausea and vomiting: an efficacy and efficiency simulation. Eur J Anaesthesiol. 2007;24(10): $856-867$.
Ambulatory Anesthesia

\section{Publish your work in this journal}

Ambulatory Anesthesia is an international, peer reviewed, open access journal publishing articles that address all aspects of ambulatory anesthesia practice, in particular: anesthetic techniques, sedation and safety practices, pharmacokinetics, preoperative evaluation, analgesia interventions, regulatory and compliance issues, postoperative recovery,
Dovepress

patient satisfaction, administrative topics, and cost analysis themes. The manuscript management system is completely online and includes a very quick and fair peer review system, which is all easy to use. Visit http://www.dovepress.com/testimonials.php to read real quotes from published authors. 